\title{
Aliased Tidal Variability in Mesoscale Sea Level Anomaly Maps
}

\author{
EDWARD D. ZARON \\ Portland State University, Portland, Oregon \\ RICHARD D. RAY \\ NASA Goddard Space Flight Center, Greenbelt, Maryland
}

(Manuscript received 31 May 2018, in final form 25 September 2018)

\begin{abstract}
Sea level anomaly (SLA) maps are routinely produced by objective analysis of data from the constellation of satellite altimeter missions in operation since 1992. Beginning in 2014, changes in the Data Unification and Altimeter Combination System (DUACS) used to create the SLA maps resulted in improved spatial resolution of mesoscale variability, but it also increased the levels of aliased tidal variability compared to the methodology employed prior to 2014. The present work investigates the magnitude and spatial distribution of these tidal signals, which are typically smaller than $1 \mathrm{~cm}$ in the open ocean but can reach tens of centimeters in the coastal ocean. In the open ocean, the signals are caused by a combination of phase-locked and phasevariable baroclinic tides. In the coastal ocean, the signals are a combination of aliased high-frequency nontidal variability and aliased variability caused by erroneous tidal corrections applied to the along-track altimetry prior to objective analysis. Several low-pass and bandpass filters are implemented to reduce the tidal signals in the mapped SLA, and independent tide gauge data are used to provide an objective assessment of the performance of the filters. The filter that attenuates both the small-scale (less than $200 \mathrm{~km}$ ) and the highfrequency (period shorter than 108 days) components of SLA removes aliased baroclinic tidal variability and improves the accuracy of tidal analysis in the open ocean while also performing acceptably in the coastal ocean.
\end{abstract}

\section{Introduction}

The multisatellite mapped sea level anomaly (SLA) products produced by the Data Unification and Altimeter Combination System (DUACS), originally distributed through Archiving, Validation, and Interpretation of Satellite Oceanographic Data (AVISO) and now distributed by the Copernicus Marine Environmental Monitoring Service (Pujol et al. 2016), have been used in hundreds of diverse oceanographic studies ( $\mathrm{Fu}$ et al. 2010; Morrow and LeTraon 2012). The maps are created by objective analysis of satellite altimeter data, which involves processing the original along-track data by applying geophysical and path delay corrections, removing the mean surface, and then gridding with prescribed spatial and temporal covariance functions (LeTraon et al. 1998; Aviso 2011; Dibarboure et al. 2011). The goal of this processing is to produce spatially homogeneous maps of ocean surface topography that

\footnotetext{
Corresponding author: Edward D. Zaron, ezaron@pdx.edu
}

have filtered out oceanic variability at time scales shorter than about 20 days and spatial scales shorter than about $200 \mathrm{~km}$ (Chelton and Schlax 2003; Mertz et al. 2016). The SLA maps are useful for inferring nearsurface geostrophic currents and associated sea level variability.

Although the SLA maps are constructed by combining independent data from the multisatellite altimeter constellation, there are errors in the resulting SLA maps that may be significant. Beginning in 2014, changes in the DUACS processing were implemented that improved the accuracy and spatial resolution of the mapped SLA (Pujol et al. 2016), but a side effect of these changes was to admit more aliased tidal variability compared to the methodology employed prior to 2014 (Ray and Zaron 2016). While it is not possible to unambiguously identify which aspects of the processing were responsible for the changes, it is hypothesized that the new along-track low-pass filtering admitted both smaller-scale mesoscale features and baroclinic tides in the mapped 
SLA. Other changes to the data selection near the coasts, satellite orbits, treatment of the mean sea surface, and improvements to the model-based wettroposphere corrections undoubtedly improved the mapped SLA for mesoscale oceanography (Pujol et al. 2016). The present work investigates the magnitude and spatial distribution of the tidal signals in the mapped SLA, which are typically smaller than $1 \mathrm{~cm}$ in the open ocean but can reach tens of centimeters in the coastal ocean.

The vast majority of tidal variance is the predictable sea level variability associated with the astronomically produced barotropic tides, which is removed when predicted barotropic tides are subtracted as a component of the geophysical correction. However, the tide models used to compute these predictions are imperfect, and any error in the models, which may be caused by errors near coastlines, omission of baroclinic tides, or omission of time-variable barotropic tides (e.g., seasonal modulations or nonlinear tides), may contribute to errors in the mapped SLA. Of course the tidal predictions are used at the precise times and locations of the altimeter measurements, prior to mapping; therefore, the errors in the tide models will be aliased to the periodicities related to the ground track repeat periods of the satellites (Parke et al. 1987). For example, for the twice-per-day lunar $\mathrm{M}_{2}$ tide, the errors will occur at a period of 62.1 days on the TOPEX/ Poseidon (T/P) ground tracks, and at the period of 94.5 days on the European Remote Sensing (ERS) ground tracks. The errors at these periods are attenuated by the mapping algorithm, which combines information from multiple ground tracks and missions; however, as shown below, the error does propagate into the mapped SLA products, and this error is significant for certain applications.

Our primary motivation for investigating the tidal signals in the SLA maps relates to how they are used when computing estimates of baroclinic tidal elevation from along-track (nongridded) altimetry. The baroclinic tide is so small that it is advantageous to remove as much nontidal variability as possible from observed sea level, prior to performing harmonic analysis. This is done by sampling the mapped SLA along the satellite ground tracks and subtracting it from the along-track measurements prior to harmonic analysis. That this leads to improved accuracy has been demonstrated by comparing baroclinic tides estimated independently at orbit crossover points (Ray and Byrne 2010; Ray and Zaron 2016), but it is obviously problematic if the mapped SLA contains a tidal signal. Particularly for investigations of non-phase-locked tidal variability, it is crucial that the residual tidal signals in the mapped
SLA be understood. Another motivation for investigating the tidal errors is related to using the mapped SLA near the coastline, where errors related to both mapping and geophysical corrections are larger than in the open ocean. Understanding and quantifying residual tidal signals in the mapped SLA will help researchers use these data in a variety of settings.

The organization of this paper is as follows. The next section illustrates tidal signals found in the mapped SLA and compares them with the baroclinic tides identified from along-track altimetry. The amplitude of tides in the mapped SLA is potentially problematic, and section 3 describes a suite of filters useful for both identifying and removing tidal variability in the mapped SLA. Section 4 then follows with a short evaluation of the filtered versions of SLA using independent data from coastal tide gauges. Finally, the results are discussed and summarized in section 5 .

\section{Examples of tidal signals in mapped SLA}

The most straightforward way to identify tidal signals in the mapped SLA is simply to harmonically analyze the SLA time series at the tidal alias periods. This methodology primarily identifies signals that are phase locked with the tide over the 25 -yr satellite altimeter era; however, nontidal variability is not completely excluded and contributes to the spatially correlated noise. As an example of this approach, Fig. 1 shows the SLA associated with the $\mathrm{M}_{2}$ tidal aliases in the vicinity of the Aleutian Islands and coastal Alaska, a region where the tides are large, rapidly varying, and fairly challenging to accurately predict (Foreman et al. 2006). A $3-\mathrm{cm}$ signal is evident near the ERS tracks in Bristol Bay, on the Alaska coast north of the Aleutians, and near T/P tracks in the mouth of Cook Inlet on the Pacific Ocean. In this case the mapping method is limited by the track spacing at the coast, which is not enough to capture small-scale processes, and by the quality of the along-track altimeter measurements in these regions (larger instrumental errors and poorer-quality geophysical corrections). The magnitude of the fields in Fig. 1 is consistent with the size of errors in tide models known to occur near the coast (Stammer et al. 2014).

It is noteworthy that tidal signals in excess of $1 \mathrm{~cm}$ are also evident close to the Aleutian Islands and throughout the region. In addition to barotropic tide correction errors, it is possible that these are related to baroclinic tides, which are not included in present-generation tide models-Goddard/Grenoble Ocean Tide, version 4.8 (GOT4.8), and Finite Element Solution, version 2014 


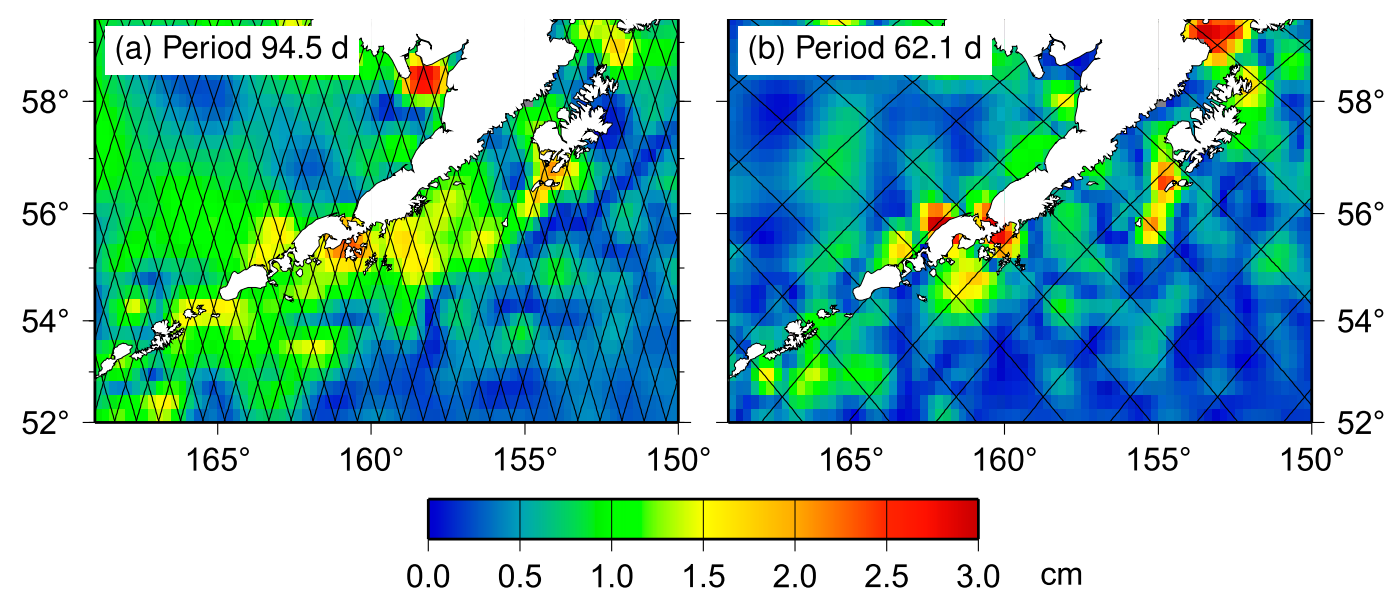

FIG. 1. Amplitudes (cm) estimated by harmonic analysis of mesoscale SLA maps near the Aleutian Islands and coastal Alaska. (a) Analysis at the 94.5-day $\mathrm{M}_{2}$ alias period for ERS shows a 3 -cm signal in Bristol Bay $\left(58^{\circ} \mathrm{N}\right.$, $158^{\circ} \mathrm{W}$ ). ERS ground tracks are overlaid for reference. (b) Analysis at the 62.1-day $\mathrm{M}_{2}$ alias period for T/P shows a $3-\mathrm{cm}$ signal in the mouth of Cook Inlet $\left(59^{\circ} \mathrm{N}, 154^{\circ} \mathrm{W}\right)$. T/P ground tracks are overlaid for reference. Smaller-scale signals near the Aleutians and a diffuse signal exceeding $1 \mathrm{~cm}$ are also evident.

(FES2014)—used for making altimeter geophysical corrections (Pujol et al. 2016). Figure 2 illustrates the results of harmonic analysis of mapped SLA in the North Pacific. The largest signals are in the western and tropical Pacific, which is consistent with the presence of a vigorous nontidal mesoscale eddy field, the signal of which leaks into the harmonic analysis. In contrast, there is a smaller signal between the Hawaiian Islands and the Aleutians, a region where baroclinic tidal signals are prominent, where it reaches centimeter amplitude. In the case of the ERS alias period, the signal consists of zonal bands (Fig. 2a), whereas the signal at the T/P alias period is more diffuse but largest along the region where a "beam" of baroclinic tidal waves is emitted from the Aleutians (Cummins et al. 2001; Zhao et al. 2011). Because the baroclinic tidal signal is only a few centimeters in amplitude, the attribution of the signals to tides or nontidal noise is ambiguous.

Clearer evidence for the baroclinic tidal nature of these signals is provided in Fig. 3. A two-dimensional wavenumber-frequency power spectrum of mapped SLA has been computed by sampling the SLA along T/P ground track 249, north of the Hawaiian Ridge, between $20^{\circ}$ and $35^{\circ} \mathrm{N}$. The SLA spectrum reveals that the variance near the T/P tidal alias (62.1 days or $0.016 \mathrm{cpd})$ is associated with a local maximum near 0.0065 cycles per kilometer (cpk), or a wavelength of $155 \mathrm{~km}$, which is approximately equal to the theoretically predicted wavelength of the mode- 1 baroclinic $\mathrm{M}_{2}$ tide at this location (Ray and Zaron 2016). Note that the frequencies and alias periods of $\mathrm{M}_{2}$ and $\mathrm{S}_{2}$ are close enough that the variance identified here is certainly a combination of both tides.
The size of the baroclinic tidal signal in the mapped SLA varies geographically. It is largest at latitudes between $10^{\circ}$ and $30^{\circ}$, partly associated with relatively large baroclinic tides, as would be expected, but this distribution might also be a consequence of the space-time covariance functions used in the objective analysis. One means of assessing the size and potential significance of the signal is to compare it with the baroclinic $\mathrm{M}_{2}$ tide estimated directly from the along-track altimetry. This is shown in Fig. 4 by integrating the two-dimensional wavenumber-frequency spectrum across the wavenumber range associated with the mode- 1 baroclinic $\mathrm{M}_{2}$ tide (bounded by the rectangle in Fig. 3) and comparing the resulting frequency spectrum with a baroclinic $\mathrm{M}_{2}$ tidal spectrum from $\mathrm{T} / \mathrm{P}$ along-track altimetry. The latter is computed by harmonic analysis of the 25 -yr record of altimetry, so its spectrum is, in principle, a delta function centered at the alias period. To make it comparable with the mapped SLA spectrum, the tidal spectrum has been modeled as a Gaussian peak centered on the alias with a bandwidth equal to $(2)^{-1}$ cycles per year (cpy), the latter being chosen subjectively to match the width of the apparent tidal peak in the SLA frequency spectrum.

The geographic locations of the spectra in Fig. 4 are shown as examples because the amplitude of the tidal peak inferred from along-track altimetry is similar-but the amplitude of the tidal peak in the mapped SLA is different-in each case. North of the Hawaiian Ridge, the SLA peak is about one-third as large as the $\mathrm{M}_{2}$ tidal peak (Fig. 4a). Because the spectra are a measure of variance, this corresponds to a root-mean-square signal that is almost $60 \%$ as large as the along-track tidal 

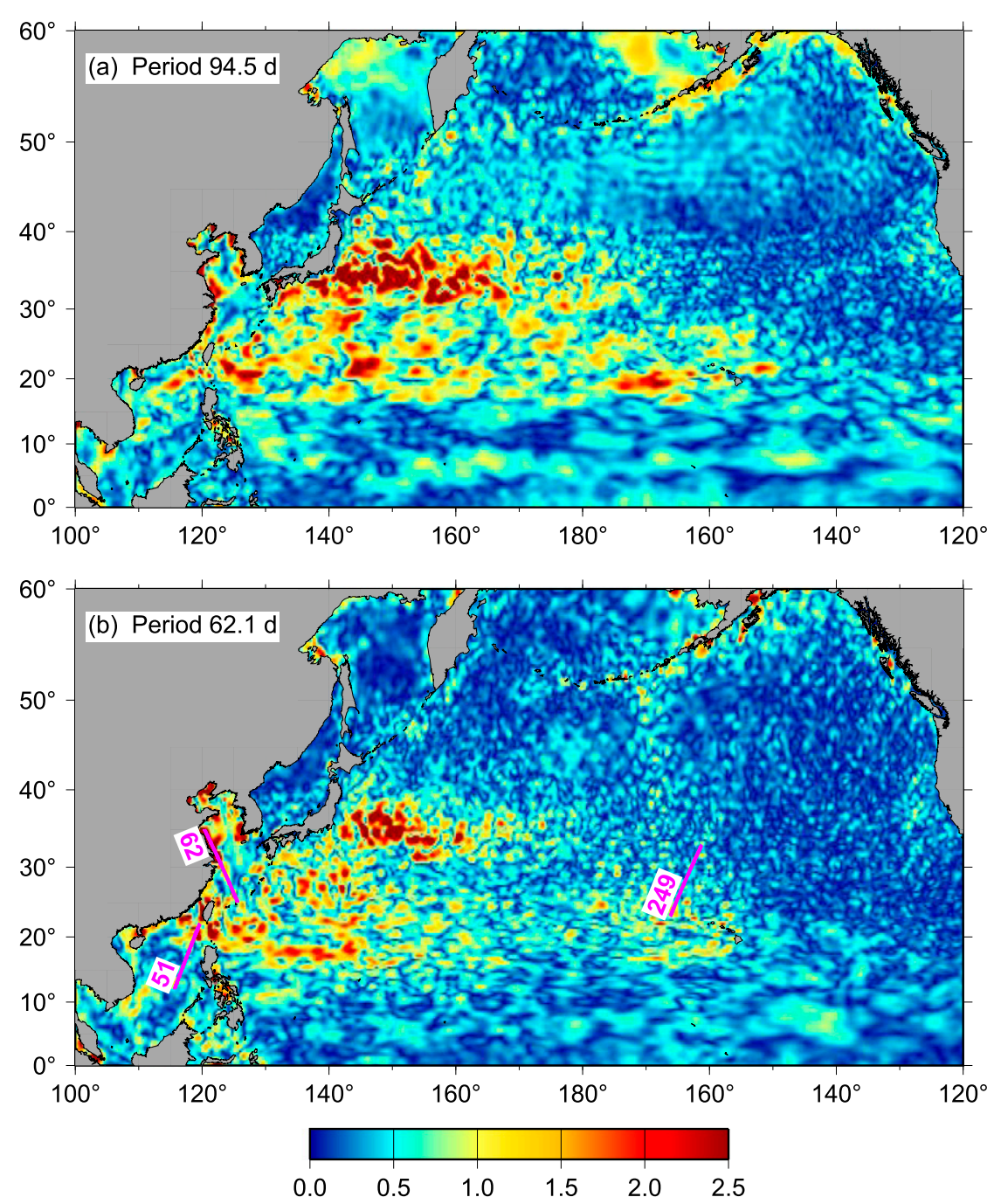

FIG. 2. Amplitudes (cm) estimated by harmonic analysis of mesoscale SLA maps in the North Pacific. (a) The $\mathrm{M}_{2}$ alias for ERS exhibits zonal stripes between the Hawaiian Islands and the Aleutians. (b) The $\mathrm{M}_{2}$ alias for T/P is elevated between the Hawaiian Islands and the Aleutians. Large signals in the western and tropical Pacific are consistent with the presence of large-amplitude nontidal mesoscale signals. Ground track segments for T/P passes 51, 62, and 249 are indicated in (b); data from these tracks are used in later figures.

signal. The amplitude of the tidal signal appears to be largest in the vicinity of the Hawaiian Ridge and, in the Southern Hemisphere, near Tuomoto (not shown). The mapped SLA tidal peak in the South China Sea is about one-quarter as large as the tide inferred from alongtrack altimetry (Fig. 4b), which is typical of the tidal signal in SLA in the $10^{\circ}-30^{\circ}$ latitude range (not shown). The mapped SLA tidal signal is much smaller elsewhere, and the region offshore from the Amazon River plume is shown as a representative example (Fig. 4c). A survey of SLA data along the interleaved T/P ground tracks and ERS ground tracks finds similar patterns of tidal alias signals (not shown). Where it is present, the tidal signal is predominantly associated with the 62-day T/P alias, rather than the 94-day ERS alias. This is thought to be the result of the sparser ground tracks of the T/P orbit versus the ERS orbit; within the region of influence of the objective analysis, the tide is sampled at more phases along ERS tracks than $\mathrm{T} / \mathrm{P}$ tracks.

Unlike the open-ocean examples just shown, the tidal alias signals in the coastal ocean can be present at large scales. Figure 5 shows data from a T/P ground track through the west side of the East China Sea. A prominent ridge in the two-dimensional wavenumberfrequency spectrum is present at $0.016 \mathrm{cpd}$, the $\mathrm{T} / \mathrm{P} \mathrm{M}_{2}$ 


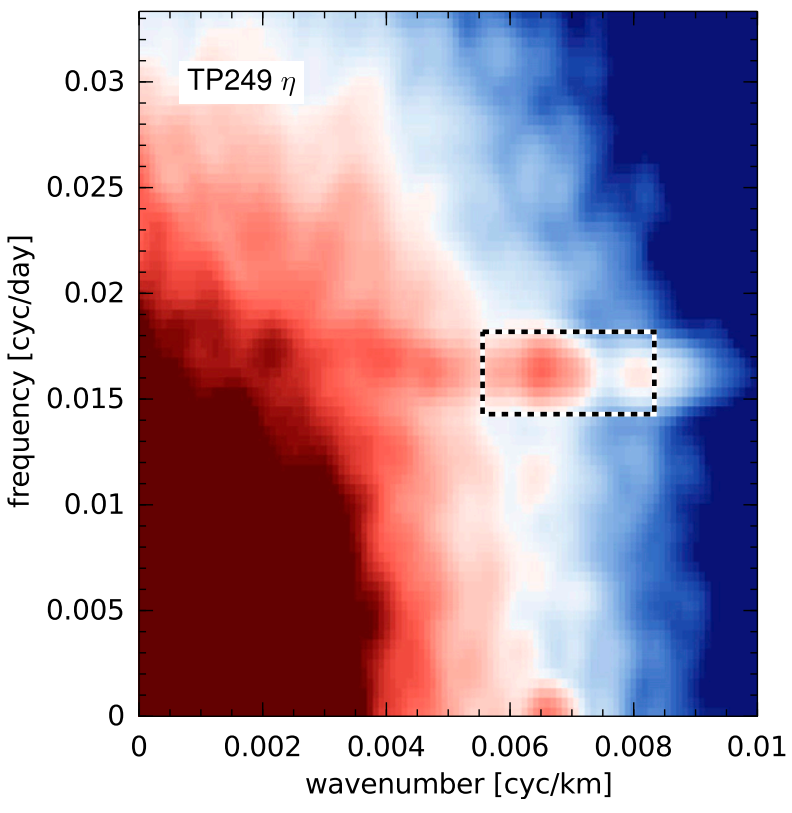

FIG. 3. Two-dimensional wavenumber-frequency spectrum of mapped SLA sampled along T/P ground track 249 , between $20^{\circ}$ and $35^{\circ} \mathrm{N}$, north of the Hawaiian Ridge. The local peak near the wavenumber of $0.0065 \mathrm{cpk}$ (155-km wavelength) and frequency of $0.016 \mathrm{cpd}$ (62.1-day period) is attributed to the mode-1 baroclinic $\mathrm{M}_{2}$ tide. Color scale ranges from 0.04 (blue) to $15 \mathrm{~m}^{2}$ (cpk cpd $)^{-1}$ (red). The dashed box delimits the wavenumber range from $1 / 120$ to $1 / 180 \mathrm{cpk}$, and the frequency range, $1 / 62.1 \mathrm{cpd} \pm 1 / 1.5 \mathrm{cpy}$. These limits are used when computing one-dimensional spectral averages in later figures.

alias frequency. The variance is largest at small wavenumbers, at much larger scales than the expected wavelength of the baroclinic tide. From this information alone, it is not clear whether the signal is caused by an erroneous ocean tide correction, by non-phase-locked barotropic tides, or by baroclinic tides sampled along an unfavorably oriented track (e.g., a track running along a $2 \mathrm{D}$ wave crest). This is known to be a region where the predictions of contemporary tide models diverge (Stammer et al. 2014). In this case the ocean tide correction is provided by the GOT4.8 (Pujol et al. 2016). This model was optimized for open-ocean-not coastal-applications, so the tidal signal in SLA is likely the result of multiple factors.

\section{Methods for identifying and removing tidal signals from mapped SLA}

Unlike the maps shown in Figs. 1 and 2, which exhibit the phase-locked variability at the tidal alias periods, the SLA spectra in Figs. 3 and 5 contain both phase-locked and non-phase-locked variance. Because the characteristics of the non-phase-locked variability are not fully understood, efforts to identify tidal signals are necessarily exploratory, and this section describes several different approaches.

A summary of the notation used to refer to different versions of filtered SLA is provided in Table 1. The unfiltered SLA is denoted $\eta$, and the filtered versions are indicated with a subscript $\eta_{X}$, where $X$ is in the set $\{$ HA, 62n, 108l, 62s, 108s\}, defined below. The complement of the filtered SLA is denoted with a hat, $\hat{\eta}_{X}=\eta-\eta_{X}$. It is useful to think of $\hat{\eta}_{X}$ as the possibly erroneous component of $\eta$ containing tidal signals and other aliased variability. In some cases the computation of the filtered field $\eta_{X}$ requires intermediate or partially filtered fields, and these fields shall be denoted with a tilde, $\tilde{\eta}_{X}$.

The first filter considered is a detided version of SLA, denoted $\eta_{\mathrm{HA}}=\eta-\hat{\eta}_{\mathrm{HA}}$. The time series of $\eta$ were harmonically analyzed at each grid point over the period 1992-2017 to obtain harmonic constants at the 62.1- and 94.5-day alias periods of $\mathrm{M}_{2}$, and these fields were used to obtain predicted tides, denoted $\tilde{\eta}_{62}$ and $\tilde{\eta}_{94}$, respectively, which were added to obtain $\hat{\eta}_{\mathrm{HA}}$. These fields are a useful benchmark for comparison with other filtered fields (Figs. 1 and 2), but as they contain only the phase-locked component of the tidal variability, it is unlikely that they would be useful for removing openocean baroclinic tidal variability, a significant fraction of which is not phase locked (Zaron 2015).

A filter for identifying and removing non-phaselocked tidal variability was implemented with a notch filter, centered at the $\lambda=2 \pi(62.1)^{-1}$ rad day $^{-1}$ frequency with a bandwidth of $\mu=2 \pi(2)^{-1} \mathrm{rad} \mathrm{yr}^{-1}$. The filter is implemented by integrating the differential equation

$$
\frac{\partial^{2} \tilde{\eta}}{\partial t^{2}}+\mu \frac{\partial \tilde{\eta}}{\partial t}+\lambda^{2} \tilde{\eta}=\mu \lambda \eta
$$

from initial conditions $\tilde{\eta}=\eta$ and $\partial \hat{\eta} / \partial t=0$, and integrating backward in time,

$$
\frac{\partial^{2} \hat{\eta}_{62 n}}{\partial t^{2}}-\mu \frac{\partial \hat{\eta}_{62 n}}{\partial t}+\lambda^{2} \hat{\eta}_{62 n}=\mu \lambda \tilde{\eta}
$$

from final conditions $\hat{\eta}_{62 n}=\tilde{\eta}$ and $\partial \hat{\eta}_{62 n} / \partial t=0$. The use of forward and backward integration makes the filter symmetric and preserves the signal phase. The SLA with this 62-day variability removed is denoted $\eta_{62 n}=\eta-\hat{\eta}_{62 n}$.

Because it is not clear a priori what bandwidth should be used for a tidal filter, another temporal filter was implemented simply to reduce all the high-frequency variability. For this purpose a symmetric Markov filter was implemented (Bennett 2002, section 3.1.6), 

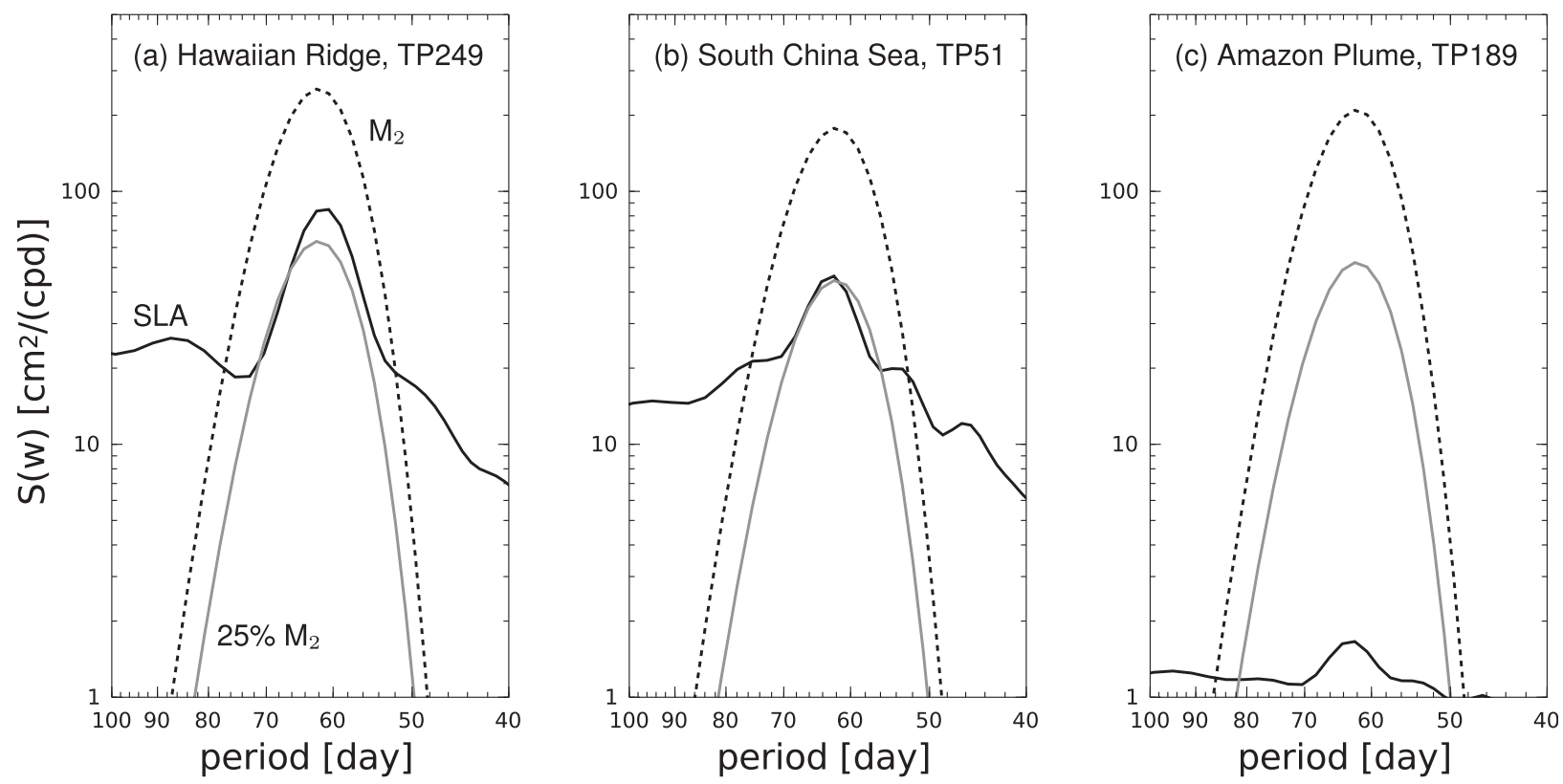

FIG. 4. Mapped SLA frequency spectra compared with along-track tides: (a) north of the Hawaiian Ridge, $23^{\circ}-33^{\circ} \mathrm{N}, \mathrm{T} / \mathrm{P}$ pass 249 ; (b) in the South China Sea, $12^{\circ}-22^{\circ} \mathrm{N}$, T/P pass 51; and (c) offshore of the Amazon River plume, $12^{\circ}-10^{\circ} \mathrm{N}, \mathrm{T} / \mathrm{P}$ pass 189 . Each panel shows the frequency spectrum of the SLA integrated across the wavenumber band encompassing the mode- 1 baroclinic $\mathrm{M}_{2}$ tide, $[1 / 180,1 / 120] \mathrm{cpk}$ (solid black line); the nominal baroclinic $\mathrm{M}_{2}$ tide, estimated from along-track harmonic analysis and distributed over alias frequency assuming a bandwidth of $1 / 2$ cpy (dashed line); and $25 \%$ of the nominal baroclinic $\mathrm{M}_{2}$ tide (solid gray line).

$$
\frac{\partial \tilde{\eta}}{\partial t}=-\lambda(\tilde{\eta}-\eta), \text { with initial condition } \tilde{\eta}=\eta \quad \text { and }
$$

$-\frac{\partial \eta_{108 l}}{\partial t}=-\lambda\left(\eta_{108 l}-\tilde{\eta}\right)$, with final condition $\eta_{108 l}=\tilde{\eta}$.

The coefficient $\lambda$ is equal to $2 \pi(108)^{-1} \mathrm{rad} \mathrm{day}^{-1}$ in this case, with this value being chosen to decrease the variance at the 62-day alias by a factor of 10 . This low-passfiltered SLA field is denoted $\eta_{108 l}$. The complementary high-frequency component $\eta-\eta_{108 l}$ is denoted $\hat{\eta}_{108 l}$.

The filters described above are confined to the time domain, and they have the undesirable property of reducing variance at all spatial scales. To better isolate and remove only the spatial scales of baroclinic tides, the temporal filters were further combined with a spatial filter. This was done by spatially low-pass filtering the bandpassed $\left(\hat{\eta}_{62 n}\right)$ and high-frequency $\left(\hat{\eta}_{108 l}\right)$ fields and adding the results back to the respective time-filtered fields. The resulting fields, denoted $\eta_{62 s}$ and $\eta_{108 s}$, respectively, retain more of the large-spatial-scale features of the original SLA than $\eta_{62 n}$ and $\eta_{108 l}$, but they have more selectively attenuated the small spatial scales. The spatial filter (200-km full width at half power) was implemented by convolution with a Gaussian kernel via pseudo-time stepping a diffusion equation on the sphere, using Neumann conditions at the coastline (Derber and Rosati 1989; Mirouze and Weaver 2010).

Maps of the variance of the fields removed by the temporal filters $\hat{\eta}_{\mathrm{HA}}$ (phase-locked tides), $\hat{\eta}_{62 n}$ (tideband variability), and $\hat{\eta}_{108 l}$ (high-frequency variability) are shown in Fig. 6 . The variance of $\hat{\eta}_{\mathrm{HA}}$ is rarely more than $1 \%$ of the SLA variance, except very close to the coastline (e.g., Fig. 6a near the Amazon River plume; cf. Figs. 1 and 2). The variance of $\hat{\eta}_{62 n}$ typically exceeds $1 \%$ of the SLA variance, and it even approaches $10 \%$ in a few areas (Fig. 6b). In comparison, the variance of $\hat{\eta}_{108 l}$ typically exceeds $10 \%$, and in some places it is larger than $30 \%$ (Fig. 6c). Note that the latter high-frequency signal $\hat{\eta}_{108 l}$ corresponds to SLA variability at periods shorter than about 100 days.

The characteristics of the different filtered versions of the mapped SLA are shown by their two-dimensional wavenumber-frequency spectra in Fig. 7 (spectra of the unfiltered SLA are in Figs. 3 and 5). Removing $\eta_{\mathrm{HA}}$ attenuates the signal at the $\mathrm{M}_{2}$ alias period, but it does not reduce it below the level of the broadband continuum (Figs. 7a and 7d). This indicates that the tidal "contamination" of the mapped SLA is caused by both phase-locked and non-phase-locked tides. In the open ocean (T/P track 249, top row), the excess variance is confined to the wavenumbers associated with the baroclinic tide; however, in the coastal ocean (T/P track 62, 


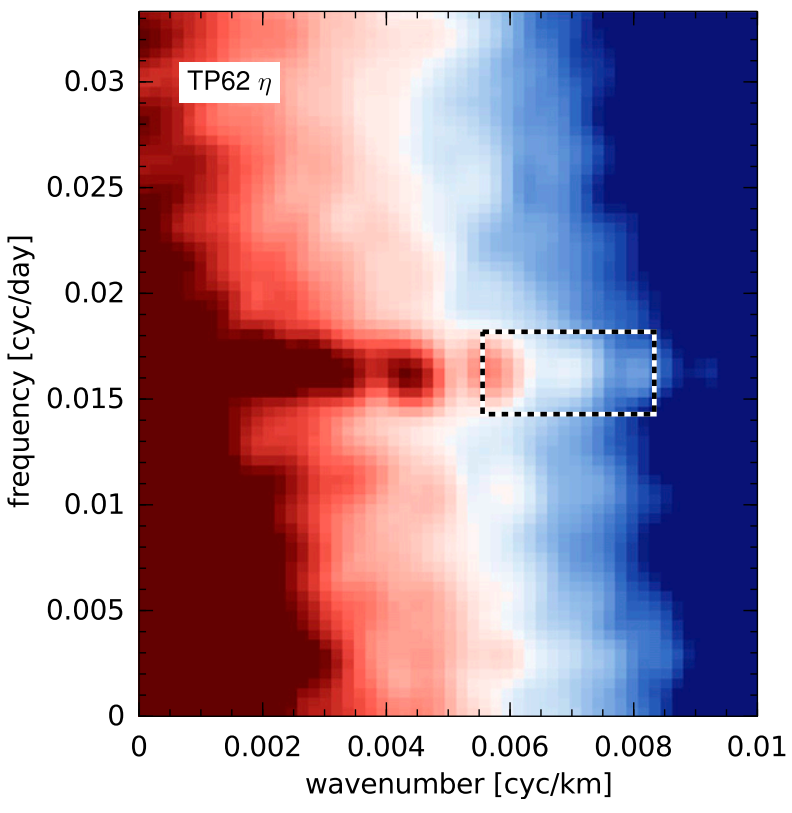

FIG. 5. Two-dimensional wavenumber-frequency spectrum of mapped SLA sampled along T/P ground track 62 through the East China Sea. The dashed box delimits the same wavenumberfrequency domain as in Fig. 3. Color scale ranges from 0.04 (blue) to $15 \mathrm{~m}^{2}$ (cpk cpd) $)^{-1}$ (red). An excess of variance at scales larger than those associated with the baroclinic $\mathrm{M}_{2}$ tide is present, which is likely a combination of barotropic coastal $\mathrm{M}_{2}$ and $\mathrm{S}_{2}$ tides.

bottom row), the excess variance extends to lower wavenumbers associated with the barotropic tide. This can be seen more clearly in the one-dimensional slices of the spectra shown in Fig. 8 (dashed lines), where the marginal spectra are obtained by integrating across the wavenumber or frequency range delimited by the rectangles plotted in Fig. 7.

The combined notch filter and spatial filter $\eta_{62 s}$ removes a narrow band of variance around the 62-day period (Figs. 7b and 7e). Considerable variance remains at large scale (small wavenumbers) in the coastal example (T/P track 62 , bottom row); this may be the result of, say, seasonal modulations of the barotropic tide that falls outside the bandwidth of the notch filter (Kang et al. 1995). The one-dimensional spectra in Fig. 8 (red lines) show that the baroclinic tidal variance in $\eta_{62 s}$ is slightly less than the nearby continuum spectrum.

The combined low-pass and spatial filter $\eta_{108 s}$ contains a baroclinic tidal peak that is approximately a factor of 10 smaller than in the unfiltered SLA (Figs. 7c and 7f). The low-pass filter has a considerable effect on the lowest frequencies, though, which are attenuated by roughly a factor of 2 (Fig. 8, heavy black lines). The temporal filter rolls off slowly, like $\omega^{-2}$ in frequency, and this explains why the high-frequency variability is such a large fraction of unfiltered SLA in this case (Fig. 6c).

The filtered fields, particularly $\eta_{108 l}$ and $\eta_{108 s}$, reduce considerably the high-frequency variability at periods associated with the oceanic mesoscale (cf. Figs. 6c, 7, and 8). While part of this variability consists of aliased tides, as intended, the rest is certainly a combination of measurement error, mapping error, mesoscale variability, and other nontidal variability. Whether the filtered fields would be useful for studies of sea level variability per se, rather than simply providing a mesoscale correction for tidal studies, is unknown, and would depend greatly on the particular application. The next section provides an evaluation of monthly mean fields intended to assess monthly variability associated with the tidal aliases.

\section{Evaluating the filtered SLA}

Ray and Byrne (2010) demonstrated that the mapped SLA could be used to remove nontidal variability from along-track altimetry and to improve the accuracy of harmonic tidal analysis. Ray and Zaron (2016) pointed out that the same approach can be used for the analysis of baroclinic tides, but they also demonstrated that changes in the objective analysis methodology implemented by DUACS in 2014 led to an increase in

TABLE 1. Symbols used to denote sea level and filtered versions of the altimeter-derived SLA. Note that the tilde is used to denote the complement of a filtered field throughout the text, e.g., $\tilde{\eta}_{\mathrm{HA}}=\eta-\eta_{\mathrm{HA}}$.

\begin{tabular}{lll}
\hline \hline Symbol & \multicolumn{1}{c}{ Name } & \multicolumn{1}{c}{ Description } \\
\hline$\eta$ & Sea level anomaly & Altimeter-derived mapped SLA \\
$\eta_{H A}$ & Detided SLA & SLA minus the predicted tide computed at ${ }_{2}$ alias periods \\
$\eta_{62 n}$ & Notch-filtered SLA & SLA minus near-(62.1) ${ }^{-1}$ cpd variability \\
$\eta_{62 s}$ & Notch-filtered and smoothed SLA & $\eta_{62 n}$ combined with spatial smoothing \\
$\eta_{108 l}$ & Low-pass-filtered SLA & Low-pass-filtered SLA with cutoff frequency of (108) ${ }^{-1}$ cpd \\
$\eta_{108 s}$ & Filtered and smoothed SLA & $\eta_{108 l}$ combined with spatial smoothing \\
$h$ & Monthly sea level & Monthly mean sea level as measured by tide gauge \\
$(\eta)_{m}$ & Monthly mean SLA & Mean of altimeter-derived SLA \\
$\left(\eta_{X}\right)_{m}$ & Monthly mean of filtered SLA & Mean of filtered SLA for $X \in\{$ HA, 62n, 108l, 62s, 108s $\}$ \\
\hline
\end{tabular}



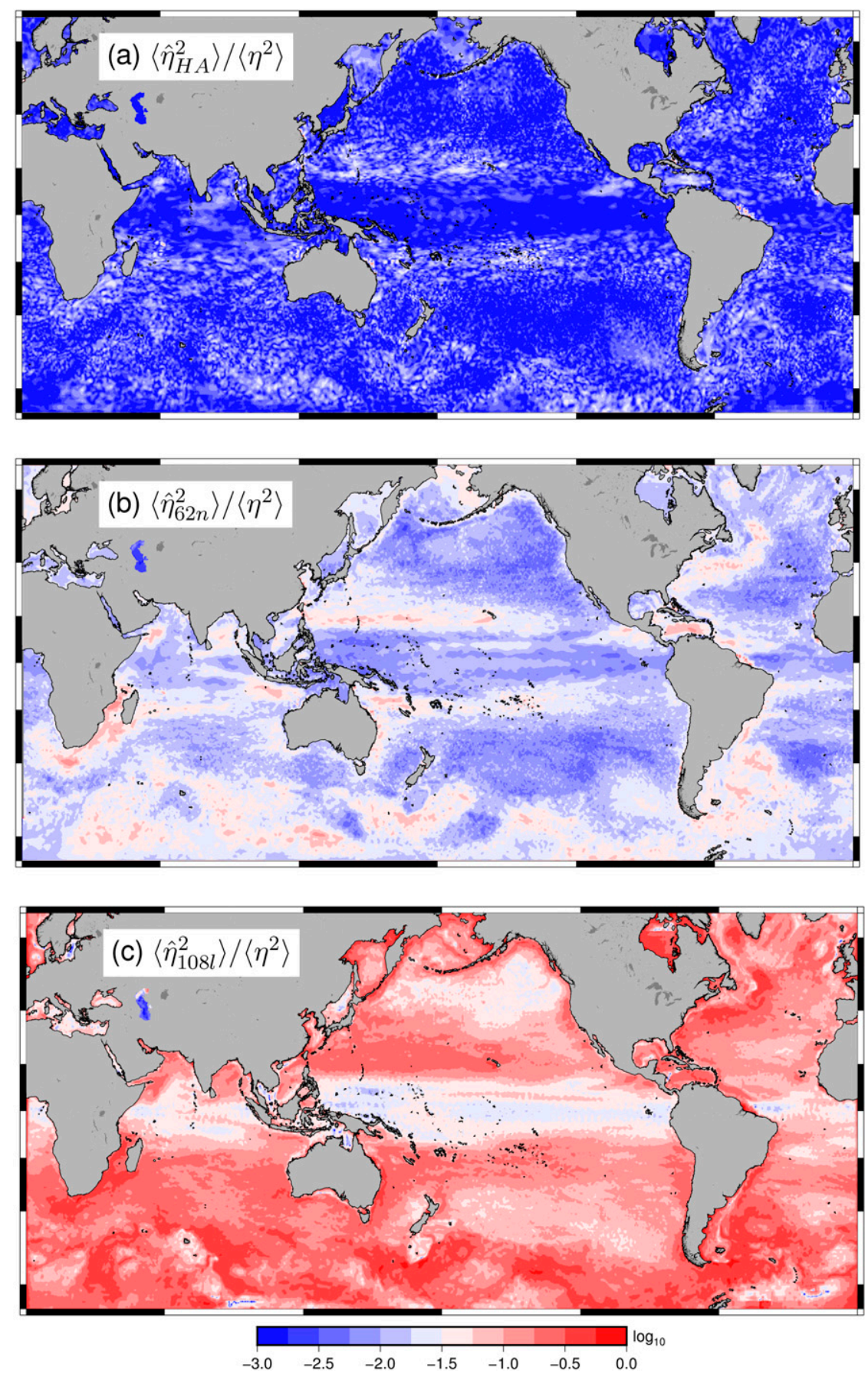

FIG. 6. Variance of the SLA correction vs total SLA variance, log scale: (a) phase-locked variability at the $\mathrm{M}_{2}$ alias periods, (b) tide-band variability, (c) high-pass variability. Note that the same color scale is used in each panel.

baroclinic tidal signals in the SLA maps and made it problematic to use these fields for the mesoscale corrections applied previously. Development of the spatially and temporally low-passed version of SLA, here denoted $\eta_{108 s}$, attenuates the open-ocean baroclinic tidal signals in the mapped SLA by about a factor of 10 , reducing them to the same or lower level as found in the pre-2014 mapped SLA product.

Analysis of the harmonic constants at orbit crossover points for the Geodetic Satellite (Geosat) Follow-On 

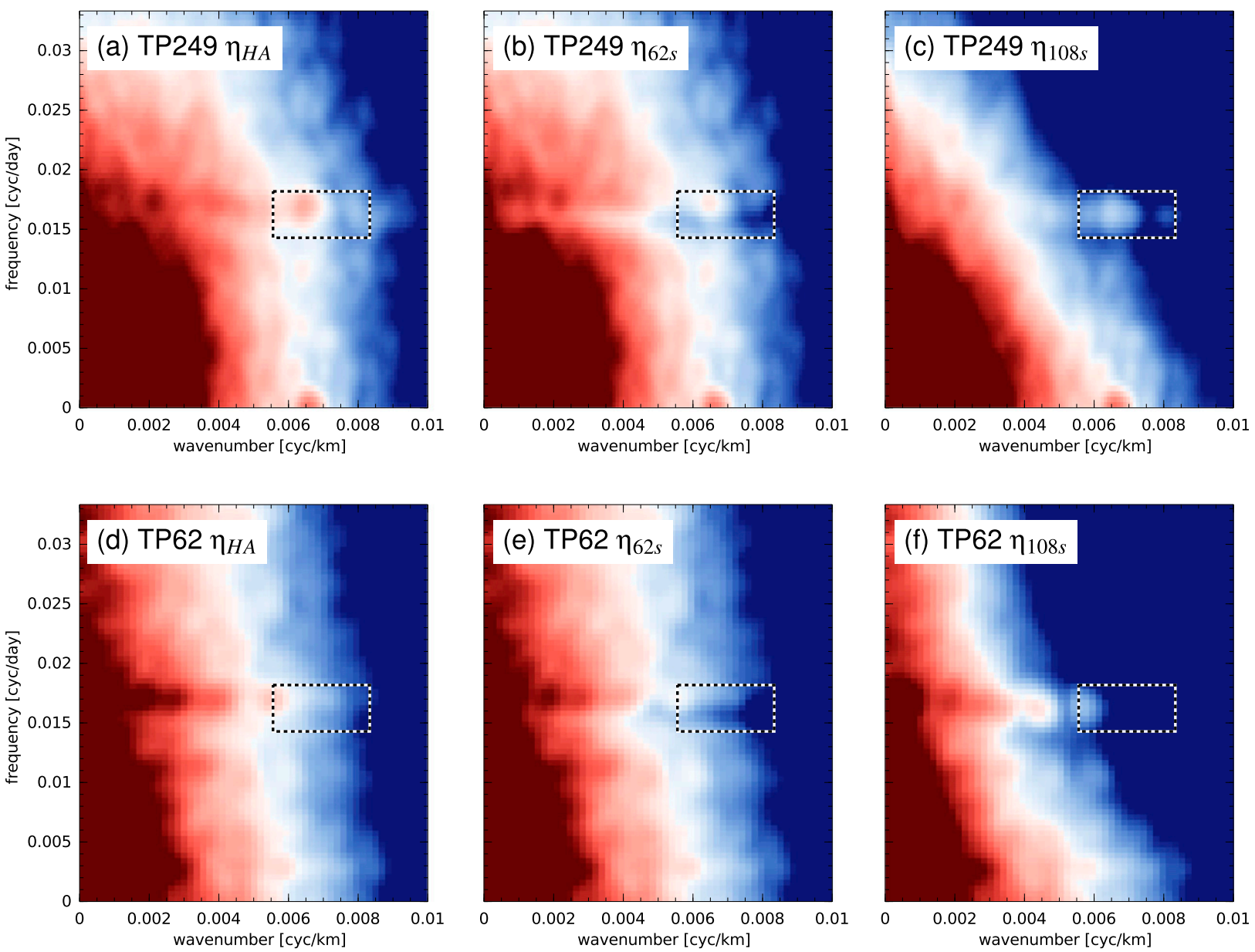

FIG. 7. Wavenumber-frequency spectra of filtered SLA in two locations: (a)-(c) in the open ocean on T/P pass 249, north of the Hawaiian Ridge (cf. Fig. 3) and (d)-(f) near the coastline on T/P pass 62 in the East China Sea (cf. Fig. 5). Columns show the spectrum of SLA when filtered to remove (a),(d) phase-locked tides; (b),(e) tide-band variability; and (c),(f) small-scale high-frequency variability. Color scale ranges from 0.04 (blue) to $15 \mathrm{~m}^{2}$ (cpk cpd) ${ }^{-1}$ (red).

$(G F O)$ mission is shown in Fig. 9. The tidal analysis of $G F O$ along-track data has been conducted as done previously (Ray and Zaron 2016), but here different versions of the filtered SLA are used to remove the nontidal variability prior to harmonic analysis. Based on what was shown above, only the two most promising versions, $\eta_{108 l}$ and $\eta_{108 s}$, are used. Also, the comparison is restricted to crossovers in the $\pm 50^{\circ}$ latitude range; otherwise, the results are heavily biased to high latitudes (where crossovers are more plentiful) and regions of very large errors (e.g., the Southern Ocean). The results are consistent with the aforementioned expectations; error is minimized in the open ocean when the space- and time-filtered field is used, $\eta_{108 s}$. Only in the region closest to the coast, $30-60 \mathrm{~km}$, does the $\eta_{108 l}$ field provide a slightly better correction, but this is at the expense of worse performance farther from the coast.
Although this analysis of harmonic constants is in some ways the most direct assessment of the filtered fields for our intended application as a correction for analysis of baroclinic tides, it is significant that it cannot directly detect tidal signals in the SLA. Spurious tidal signals in the SLA would be present in the data from both the ascending and descending tracks, and it would not contribute to the error estimated by differencing these harmonic constants. This is especially relevant approaching the coastline (Fig. 1), where tide models are known to exhibit increased errors related to erroneous or sparse bathymetric data, small-scale features not resolved by the model grids, poorly represented nonlinear dynamics, and sparse coastal tide gauge data available for assimilation (Cheng and Andersen 2011; Ray et al. 2011). An inspection of global versions of the maps corresponding to Figs. 1 and 2 indicates that the largest coastal signals associated with the 62.1-day alias 

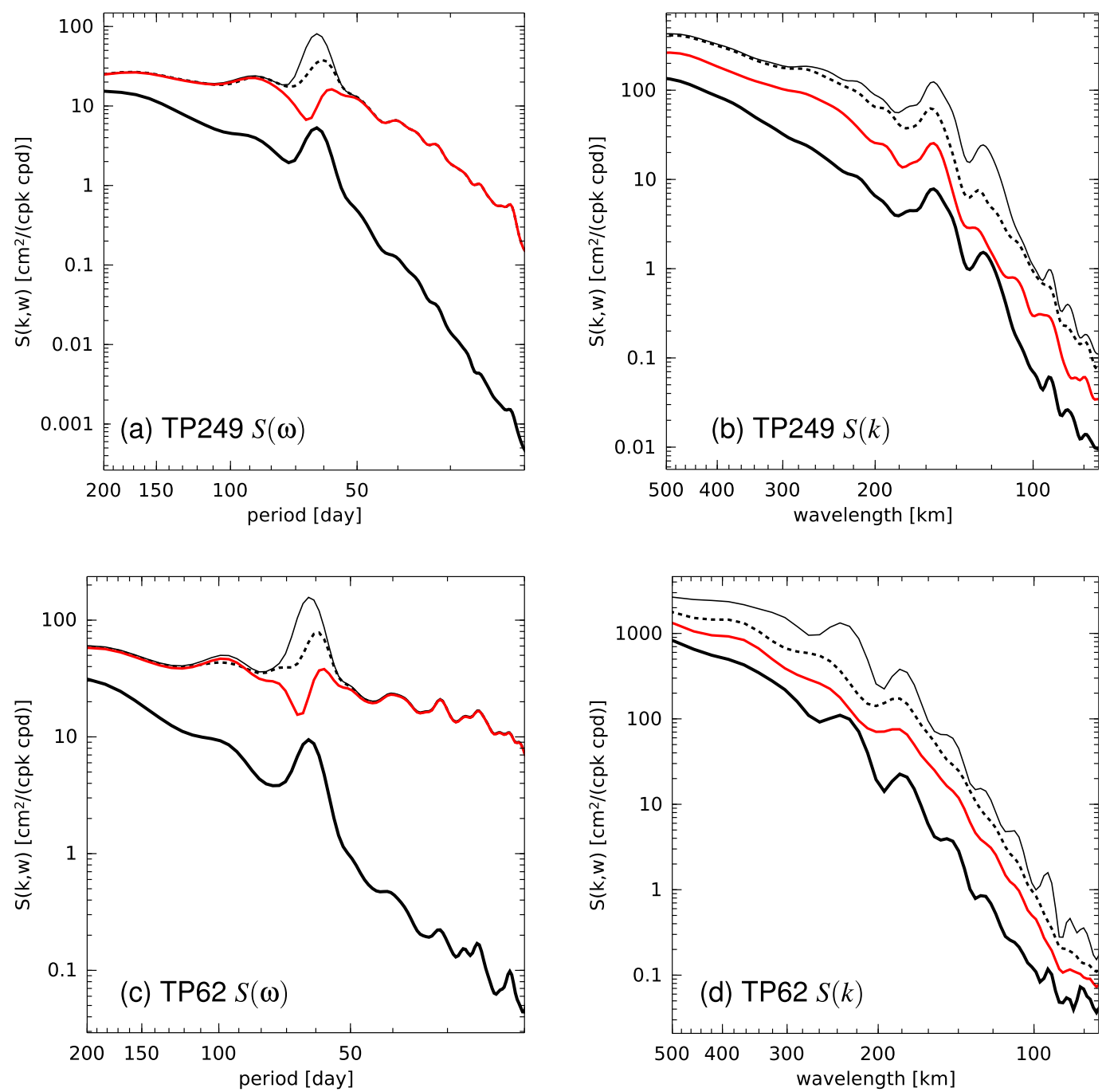

FIG. 8. One-dimensional spectra of filtered SLA in two locations: (a),(b) in the open ocean on T/P pass 249 and (c),(d) near the coastline on T/P pass 62. (left) Frequency spectra of the unfiltered SLA $\eta$ (thin black line), detided SLA $\eta_{\mathrm{HA}}$ (dashed line), notch-filtered SLA $\eta_{62 s}$ (red line), and low-pass-filtered SLA $\eta_{108 s}$ (thick black line) show the extent to which each filter attenuates the tidal peak near the 62-day alias period. (right) Wavenumber spectra illustrate the scale dependence of the filtering; note that removal of $\eta_{\mathrm{HA}}$ (dashed line) attenuates the signal at large scales on T/P track 62 .

are found along the west coast of the East China Sea, on the northeast side of the Gulf of Arabia, and at sites along the northern coasts of Australia. Coastal SLA signals at the 94.5-day alias are found at many of the same regions, but they are coherent at smaller scales likely because of the smaller intertrack spacing of the ERS tracks.

To detect tidal signals in the SLA fields, independent data from the coastal tide gauge network has been used. Neither the SLA maps nor the tidal corrections are optimized for use right up to the coastline; however, the SLA maps are commonly used to infer regional sea level trends and to compare with the tide gauge network, yielding useful results (e.g., Merrifield 2011; Ruiz Etcheverry et al. 2015). For comparison here, monthly mean sea level records were obtained from the Permanent Service for Mean Sea Level (PSMSL; extracted from the database on 2 April 2018; Holgate et al. 2013) and screened to retain those records with at least 10 years of data between 1993 and 2018, and within the latitude range $\pm 50^{\circ}$. A total of 591 stations were found meeting these criteria. Because the tidal alias period is longer than a month, one would expect tide model errors to contribute significantly to error in monthly averages.

It is not feasible to study each gauge in detail, but an example illustrates the coastal variability of the filtered 


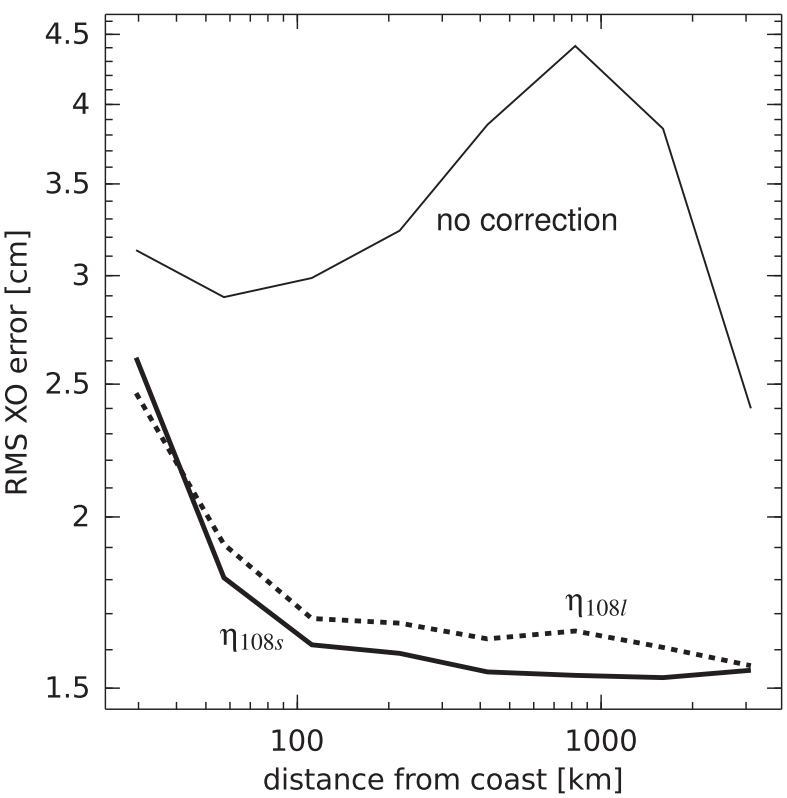

FIG. 9. Accuracy of $\mathrm{M}_{2}$ harmonic constants computed from $G F O$ data at crossovers in the range of $\pm 50^{\circ}$ latitude. Root-mean-square difference in the harmonic constants (in phase and quadrature) between ascending and descending passes is about $3.5 \mathrm{~cm}$ when no "mesoscale correction" is used (thin solid line). Optimal results are obtained in the open ocean when the filtered SLA field $\eta_{108 s}$ is used for the correction (heavy solid line). Slight improvement is obtained in the near-coastal region, $30-60 \mathrm{~km}$ from the coast, if the $\eta_{108 l}$ is used (dashed line).

SLA fields. Figure 10 shows the locations of the Lusi and Kanmen tide gauges in the East China Sea, near T/P track 62, spectra from which were shown above. The 62-day-band variability $\hat{\eta}_{62 n}$ is prominent near Lusi but much less so near Kanmen (Fig. 10a). In contrast, highfrequency variability $\hat{\eta}_{108 l}$ extends over a larger region of the coastline in this area (Fig. 10b). This is a region with shallow, rapidly changing bathymetry (Xie et al. 2013; Song et al. 2013) and nonlinear tides (Lefevre et al. 2000), so it seems plausible that errors in the tide model used for the geophysical corrections would be significant here.

To compare filtered SLA with tide gauge data, it is necessary to compute monthly average SLA, which shall be denoted $\left(\eta_{X}\right)_{m}$, for subscript $X$ in the set used above. In the case of Lusi, the variance of observed monthly mean sea level is $\sigma_{h}^{2}=219 \mathrm{~cm}^{2}$, while the variance of the monthly mean unfiltered SLA is larger, $\sigma^{2}=377 \mathrm{~cm}^{2}$. Let $\Delta_{X}^{2}=\left\langle\left[h-\left(\eta_{X}\right)_{m}\right]^{2}\right\rangle$ denote the variance of the difference of the monthly means; for unfiltered SLA this quantity is $\Delta^{2}=290 \mathrm{~cm}^{2}$. For the filtered SLA, one finds $\Delta_{62 n}^{2}=223 \mathrm{~cm}^{2}, \Delta_{108 s}^{2}=186 \mathrm{~cm}^{2}$, and $\Delta_{108 \mathrm{l}}^{2}=136 \mathrm{~cm}^{2}$. In other words, at Lusi the residual variance between $h$ and filtered versions of $\eta$ is steadily improved as more of the high-frequency part of the SLA is removed. This outcome is consistent with Fig. 9, which suggested that the $\eta_{108 l}$ version of mapped SLA is most accurate near the coastline.

The degree to which Lusi may be a special case, though, is unknown without a more comprehensive comparison. Such a comparison is shown in Table 2, which lists these same statistics for a subset of the PSMSL stations. The subset of stations shown are those for which the residual statistic changes the most, depending on whether the $\eta_{108 s^{-}}$or $\eta_{108 l^{-}}$filtered versions
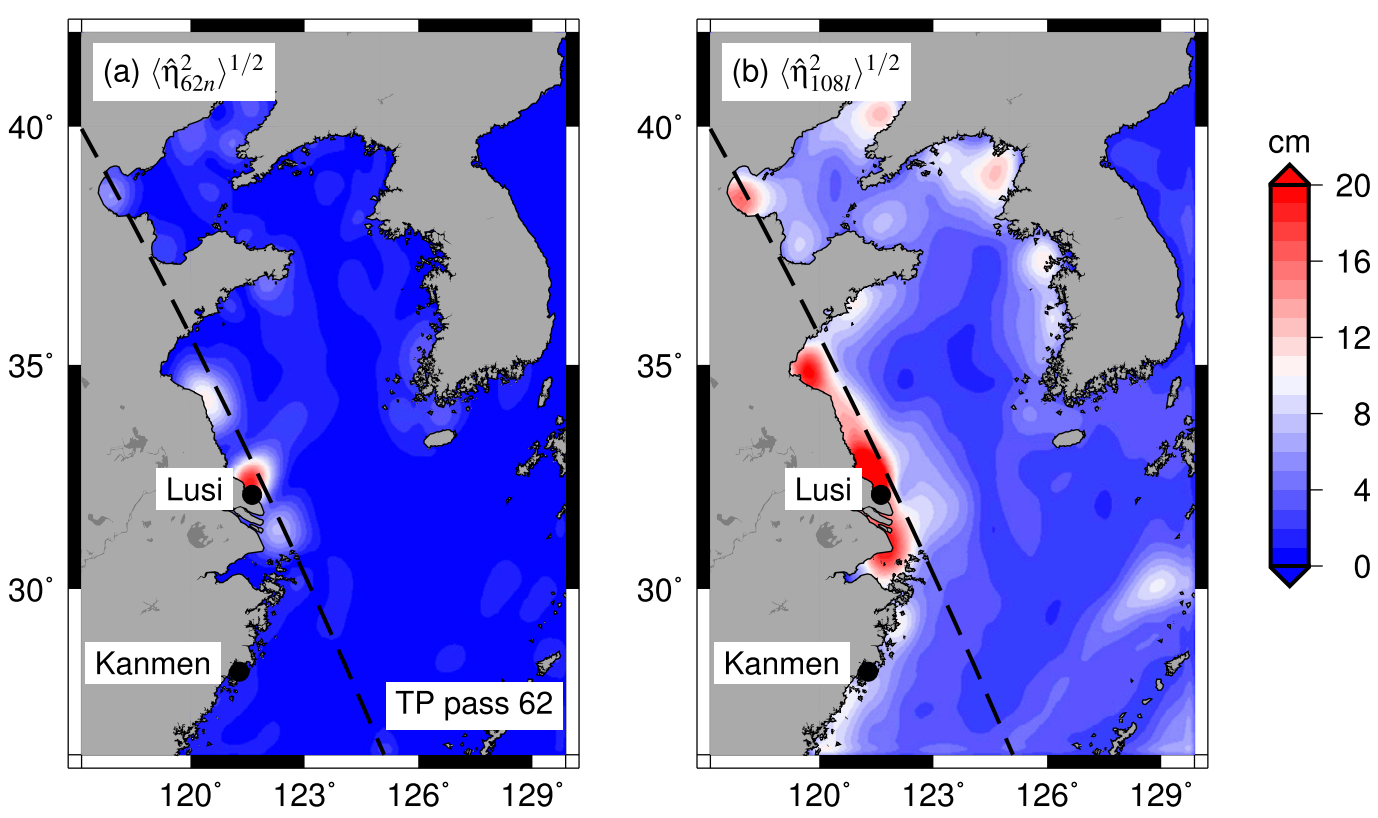

FIG. 10. East China Sea, showing standard deviation of (a) $\hat{\eta}_{62 n}$ and (b) $\hat{\eta}_{108 l}$. 
TABLE 2 . Tide gauge comparison: the 20 best and 20 worst, sorted by $\Delta_{108 s}^{2}-\Delta_{108 l}^{2}$. Variance of monthly mean $h$ and monthly mean $\eta$ are denoted $\sigma_{h}^{2}$ and $\sigma^{2}$, respectively; $\Delta_{X}^{2}$ denotes the variance of the difference $h-\left(\eta_{X}\right)_{m}$.

\begin{tabular}{|c|c|c|c|c|c|c|c|c|c|c|}
\hline \multirow[b]{2}{*}{ ID } & \multirow[b]{2}{*}{ Name } & \multirow[b]{2}{*}{ Lat $\left({ }^{\circ} \mathrm{N}\right)$} & \multirow[b]{2}{*}{ Lon $\left({ }^{\circ} \mathrm{E}\right)$} & \multicolumn{7}{|c|}{ Variance $\left(\sigma^{2}\right.$ and $\left.\Delta^{2}\right)$ and std error $\left(\varepsilon ; \mathrm{cm}^{2}\right)$} \\
\hline & & & & $\sigma_{h}^{2}$ & $\sigma^{2}$ & $\Delta^{2}$ & $\Delta_{62 n}^{2}$ & $\Delta_{108 s}^{2}$ & $\Delta_{108 l}^{2}$ & $\varepsilon\left(\Delta_{108 s}^{2}\right)$ \\
\hline 1440 & Kaminato II & 33.1 & 139.8 & 1057.9 & 1031.5 & 56.1 & 55.2 & 61.0 & 112.1 & \pm 5 \\
\hline 1451 & Hiron Point & 21.8 & 89.5 & 669.0 & 148.3 & 249.7 & 249.1 & 247.8 & 275.4 & \pm 31 \\
\hline 1060 & Miyake Sima & 34.1 & 139.5 & 899.1 & 227.0 & 514.1 & 513.6 & 513.9 & 540.2 & \pm 42 \\
\hline 1157 & Weipa & -12.7 & 141.9 & 687.9 & 267.6 & 123.8 & 125.6 & 130.2 & 155.5 & \pm 11 \\
\hline 1369 & Gangra & 21.9 & 88.0 & 462.4 & 102.9 & 216.1 & 214.2 & 211.3 & 228.6 & \pm 23 \\
\hline 1270 & Haldia & 22.0 & 88.1 & 452.6 & 53.6 & 286.3 & 284.7 & 281.6 & 297.8 & \pm 25 \\
\hline 543 & Diamond Harbour & 22.2 & 88.2 & 479.7 & 53.0 & 312.6 & 310.6 & 306.3 & 321.9 & \pm 27 \\
\hline 1703 & Geting & 6.2 & 102.1 & 297.2 & 180.0 & 29.3 & 29.3 & 29.2 & 43.8 & \pm 2 \\
\hline 2328 & New Canal Station & 30.0 & 269.9 & 171.5 & 56.9 & 75.5 & 74.8 & 71.9 & 86.3 & \pm 9 \\
\hline 828 & Galveston I & 29.3 & 265.2 & 144.2 & 54.1 & 41.4 & 41.3 & 41.8 & 55.9 & \pm 4 \\
\hline 1160 & Milner Bay & -13.9 & 136.4 & 491.6 & 371.9 & 23.5 & 22.9 & 21.4 & 34.2 & \pm 2 \\
\hline 2326 & Mayport & 30.4 & 278.6 & 166.8 & 112.6 & 21.7 & 21.2 & 20.4 & 32.9 & \pm 2 \\
\hline 112 & Fernandina Beach & 30.7 & 278.5 & 147.7 & 96.7 & 25.4 & 25.1 & 24.3 & 36.6 & \pm 2 \\
\hline 723 & Dalian & 38.9 & 121.7 & 307.0 & 94.4 & 118.8 & 116.0 & 113.0 & 125.2 & \pm 9 \\
\hline 818 & Lord Howe Island & -31.5 & 159.1 & 216.4 & 215.4 & 28.9 & 29.0 & 30.9 & 42.5 & \pm 3 \\
\hline 2215 & Bay Waveland & 30.3 & 270.7 & 157.6 & 64.5 & 48.5 & 48.2 & 47.0 & 58.4 & \pm 6 \\
\hline 161 & Galveston II & 29.3 & 265.2 & 151.1 & 61.7 & 40.3 & 40.3 & 40.9 & 52.2 & \pm 3 \\
\hline 764 & La Paloma & -34.6 & 305.9 & 223.2 & 56.4 & 143.5 & 143.0 & 142.1 & 153.4 & \pm 12 \\
\hline 725 & Freeport & 28.9 & 264.7 & 122.0 & 57.9 & 28.7 & 29.0 & 31.5 & 42.5 & \pm 3 \\
\hline 395 & Fort Pulaski & 32.0 & 279.1 & 145.2 & 97.1 & 41.7 & 40.0 & 36.9 & 47.7 & \pm 3 \\
\hline 841 & Hondau & 20.7 & 106.8 & 87.0 & 115.9 & 57.4 & 56.4 & 54.5 & 49.2 & \pm 5 \\
\hline 2073 & Urangan II & -25.3 & 152.9 & 40.2 & 76.8 & 76.8 & 58.3 & 48.1 & 42.2 & \pm 4 \\
\hline 454 & St. Malo & 48.6 & 358.0 & 68.4 & 84.0 & 85.7 & 77.1 & 56.1 & 49.9 & \pm 5 \\
\hline 1154 & Bundaberg & -24.8 & 152.4 & 67.1 & 95.9 & 94.4 & 46.6 & 42.1 & 35.6 & \pm 4 \\
\hline 1351 & Raffles & 1.2 & 103.8 & 62.2 & 70.6 & 34.4 & 29.3 & 25.9 & 18.5 & \pm 2 \\
\hline 1895 & West Coast & 1.3 & 103.8 & 67.9 & 85.7 & 30.2 & 25.7 & 22.9 & 15.5 & \pm 2 \\
\hline 1795 & St. Helier 2 & 49.2 & 357.9 & 78.8 & 105.8 & 106.6 & 95.6 & 66.0 & 58.0 & \pm 6 \\
\hline 1760 & Rosslyn Bay & -23.2 & 150.8 & 70.2 & 79.8 & 90.6 & 78.5 & 54.3 & 46.2 & \pm 5 \\
\hline 1248 & Sultan Shoal & 1.2 & 103.7 & 54.8 & 70.7 & 36.4 & 31.1 & 27.9 & 19.1 & \pm 2 \\
\hline 935 & Darwin & -12.5 & 130.8 & 157.6 & 138.3 & 79.5 & 72.0 & 56.4 & 47.3 & \pm 5 \\
\hline 1677 & Kukup & 1.3 & 103.4 & 60.8 & 64.1 & 48.5 & 43.2 & 40.2 & 31.0 & \pm 3 \\
\hline 1894 & Tuas & 1.3 & 103.7 & 54.1 & 75.5 & 35.7 & 31.4 & 28.7 & 19.3 & \pm 3 \\
\hline 444 & Fort Phrachula & 13.6 & 100.6 & 191.8 & 175.8 & 147.0 & 137.7 & 119.5 & 109.8 & \pm 10 \\
\hline 394 & Cebu & 10.3 & 123.9 & 89.4 & 89.6 & 42.5 & 39.5 & 37.5 & 26.5 & \pm 3 \\
\hline 1896 & West Tuas & 1.3 & 103.6 & 53.6 & 77.2 & 43.1 & 37.4 & 34.8 & 23.4 & \pm 3 \\
\hline 1749 & Turtle Head & -10.5 & 142.2 & 180.3 & 297.7 & 89.6 & 82.7 & 67.7 & 51.0 & \pm 7 \\
\hline 1300 & Ince Point & -10.5 & 142.3 & 69.6 & 161.5 & 73.9 & 65.0 & 48.3 & 31.1 & \pm 5 \\
\hline 1569 & Shute Harbour 2 & -20.3 & 148.8 & 73.9 & 150.7 & 133.8 & 118.9 & 79.5 & 54.4 & \pm 7 \\
\hline 1246 & Hay Point & -21.3 & 149.3 & 88.1 & 253.8 & 263.6 & 238.8 & 165.6 & 122.1 & \pm 14 \\
\hline 979 & Lusi & 32.1 & 121.6 & 218.6 & 376.8 & 289.6 & 223.0 & 185.8 & 135.8 & \pm 15 \\
\hline 564 & Mackay & -21.1 & 149.2 & 85.9 & 265.5 & 281.3 & 254.0 & 165.0 & 112.4 & \pm 14 \\
\hline
\end{tabular}

are used, as measured by $\Delta_{108 s}^{2}$ and $\Delta_{1081}^{2}$, respectively. The rows in Table 2 are sorted according to $\Delta_{108 s}^{2}-\Delta_{1088}^{2}$, showing only those 20 stations with extremal positive and negative values of this statistic. Positive values of this difference indicate that the $\left(\eta_{108 l}\right)_{m}$ field agrees better with observed $h$ than $\left(\eta_{108 s}\right)_{m}$; Lusi is near the bottom of the list.

It is instructive to dwell on this table in some detail. Among all those stations where $\eta_{108 s}$ is better than $\eta_{108 l}$, the median difference is only $-2.7 \mathrm{~cm}^{2}$, but among these 20 extreme cases shown, the difference ranges from -50 to $-10 \mathrm{~cm}^{2}$ (the top half of the table; $\Delta_{108 s}^{2}-\Delta_{108 l}^{2}<0$ ).
The opposite case, where $\eta_{108 /}$ is better than $\eta_{108 s}$, has a median difference of only $1.3 \mathrm{~cm}^{2}$, but the range among the 20 largest cases is $5-53 \mathrm{~cm}^{2}$ (the bottom half of the table; $\left.\Delta_{108 s}^{2}-\Delta_{108 l}^{2}>0\right)$. Thus, at the vast majority of stations, there is very little difference between the filtered versions, but at a small number of stations the difference is extreme. Note, for reference, the median difference in variance of $h-(\eta)_{m}$ versus $h-\left(\eta_{108 s}\right)_{m}$ is only $0.97 \mathrm{~cm}^{2}$. In other words, the impact of the filtering at the coastline is typically very small but broadly consistent with a few-centimeter error in the barotropic tidal correction at the coast. 
The entry in the last column of Table 2, denoted $\varepsilon\left(\Delta_{108 s}^{2}\right)$, is the expected standard error in the sample estimate of $\Delta_{108 s}^{2}$. It provides a useful reference for assessing the significance of the differences between the residual variances. In most cases the magnitude of the difference, $\Delta_{108 s}^{2}-\Delta_{108 l}^{2}$, is larger than the standard error.

Figure 11 illustrates the residual variance $\Delta_{108 s}^{2}$ as a function of nearby water depth, where the latter is defined at the maximum ocean depth within $50 \mathrm{~km}$ of the station. The variance, and the range from minimum to maximum, is a strong function of nearby water depth, with largest values generally occurring in association with the shallowest water.

There are few conclusions to be drawn without a detailed examination of the stations. Among the stations in the top half of the table, at all but two gauges (1157 Weipa and 818 Lord Howe Island) the tide-band-filtered SLA $\eta_{62 n}$ explains more variance than the unfiltered SLA $\eta$. In 13 out of the 20 cases, there is a further reduction in variance for the $\eta_{108 s}$ version. But in all cases the variance increases greatly for the $\eta_{108 l}$ version. Thus, for these stations there is a small spurious tidal signal near the 62-day alias, but it is not a broadband or largescale error.

Among stations in the bottom half of the table, there is benefit from each successive increase in the amount of filtering. In these cases the high-frequency variability of $\eta$ is uncorrelated with observed sea level, regardless of spatial scale. While it is possible that $\eta$ contains an erroneous tidal signal that contributes to the errormost of these stations are located along the northern coasts of Australia and within the East China Sea, where contemporary tide models disagree (Stammer et al. 2014) - the results may indicate deficient highfrequency altimeter corrections or problems with objective analysis in these areas.

In summary, use of the $\eta_{108 s}$ version of the mapped SLA to remove nontidal variance prior to harmonic analysis is of unambiguous benefit in the open ocean, where the noise caused by nontidal mesoscale sea level variability is greatly reduced, and the use of this correction does not add a significant spurious baroclinic tidal signal. In the coastal ocean, the use of $\eta_{108 s}$ will also attenuate error caused by small-scale highfrequency signals. It is probably not advisable to use the $\eta_{108 l}$ version of the filtered SLA for this purpose. Although $\eta_{108 l}$ better reduces the error of harmonic analysis of altimeter data close to the coast, at some locations it substantially increases the error when compared with independent coastal tide gauge data. Because the $\eta_{108 s}$ field is filtered in both time and space, it selectively attenuates the noise in the unfiltered $\eta$ field.

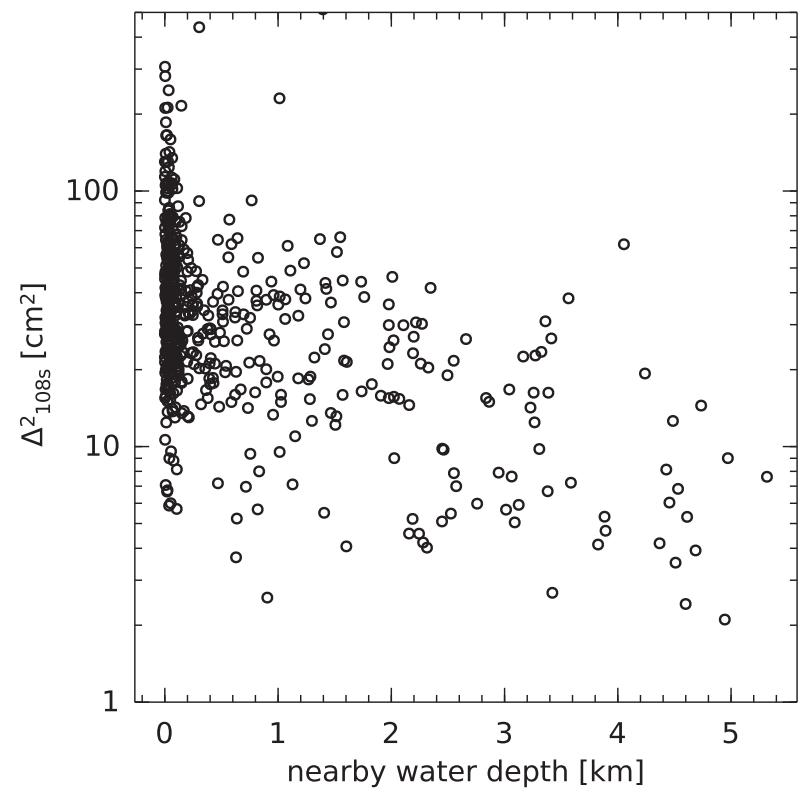

FIG. 11. Error, mean-square monthly mean $\left(\eta_{108 s}\right)_{m}$ minus PSMSL $h$, as a function of nearby water depth. Nearby water depth is defined as the depth of the deepest water within $50 \mathrm{~km}$ of each station, according to the General Bathymetric Chart of the Oceans GEBCO (topography). There is a general trend for stations in deeper water to exhibit smaller errors; however, the range of error is very large at all depths.

\section{Discussion and summary}

Ray and Zaron (2016) documented the existence of baroclinic tides in the version of the mesoscale SLA maps produced by DUACS beginning in 2014. Changes in the map resolution and temporal frequency (from weekly to daily) occurred at the same time as other processing changes intended to improve and homogenize the product over the, then, 21-yr altimeter era (Aviso 2014). The analysis conducted here replicates those findings and identifies strategies for filtering the newer SLA maps in order to make them useful for removing mesoscale variability from altimeter time series for tidal applications. Among the filters used here, the version that removes both high-frequency $(<108$-day period) and small-scale $(<200-\mathrm{km}$ wavelength) variability reduces the baroclinic semidiurnal tidal variance by a factor of 10 or more. Filters that remove variability near the T/P 62-day $\mathrm{M}_{2}$ alias reduce the variability by about a factor of 5. Note that identification and removal of variability associated with the dominant diurnal baroclinic tide $\mathrm{K}_{1}$ has not been attempted and is likely not feasible using the present approaches. The T/P alias period, 173 days, and the wavelength, around $300 \mathrm{~km}$, place it well within the continuum of mesoscale variability.

It is less clear how to use the SLA maps near the coastline. Both nontidal and tidal sea level variability 
are, generally, larger approaching the coast, so the removal of coastal SLA from time series prior to harmonic analysis ought to lead to more accurate results, just as it does in the open ocean. The usefulness of the DUACS-mapped SLA for this purpose is dubious though, since the dynamical processes near the coasts are distinct from the open-ocean mesoscale dynamics and the objective analysis methodology is likely suboptimal. Furthermore, the environmental corrections, including the ocean tide corrections and the dynamic atmospheric loading corrections (Carrère and Lyard 2003), contain larger errors near the coast, and the spacing of satellite ground tracks is sparse and not homogeneous, so the SLA maps are unavoidably less accurate in coastal regions.

Nonetheless, the comparison with independent tide gauge data has illustrated the degree to which aliased high-frequency variability in the mesoscale maps can lead to errors. As interest increases in the use of altimetry for coastal studies (Vignudelli et al. 2011), the present results indicate how difficult it may be to correct for or remove aliased variability. The small spatial scales involved dictate that the interpretation of SLA maps near the coast must proceed on a case-by-case basis. The tentative conclusion is that the space- and time-filtered version of the mapped SLA, denoted $\eta_{108 s}$, provides the best estimate of nontidal SLA for studies of coastal and open-ocean tides with altimetry. Future improvements in accuracy will result when internal tide corrections are directly applied to the along-track altimeter data prior to mapping.

Acknowledgments. Many scientists and project managers have contributed to the assembly and archival of freely available and high-quality tide gauge and satellite altimeter datasets, and their efforts are greatly appreciated. The mesoscale sea level anomaly maps were provided by the Copernicus Marine and Environment Monitoring Service (CMEMS; http:// marine.copernicus.eu/). The along-track altimetry data were obtained using the Radar Altimeter Database System (RADS; http://rads.tudelft.nl/rads/rads. shtml), which is an effort of the Department of Earth Observation and Space Systems at TU Delft and the NOAA Laboratory for Satellite Altimetry. The monthly average sea level data were provided by the Permanent Service for Mean Sea Level (http:// www.psmsl.org/). This project was supported by NASA Grants NNX17AJ35G and NNX16AH88G, and National Geospatial-Intelligence Agency Grant HM01771310008. The filtered SLA products and processing tools may be obtained by request from the corresponding author.

\section{REFERENCES}

Aviso, 2011: SSALTO/DUACS user handbook: (M)SLA and (M)ADT near-real time and delayed time products. Issue 2.6, Tech. Rep. CLS-DOS-NT-06-034, 57 pp.

_ 2014: A new version of SSALTO/DUACS products available in April 2014. Issue 1.1, 32 pp., https://www.aviso.altimetry.fr/ fileadmin/documents/data/duacs/Duacs2014.pdf.

Bennett, A. F., 2002: Inverse Modeling of the Ocean and Atmosphere. Cambridge University Press, $234 \mathrm{pp}$.

Carrère, L., and F. Lyard, 2003: Modelling the barotropic response of the global ocean to atmospheric wind and pressure forcing-Comparisons with observations. Geophys. Res. Lett., $\mathbf{3 0}$, 1275, https://doi.org/10.1029/2002GL016473.

Chelton, D. B., and M. G. Schlax, 2003: The accuracies of smoothed sea surface height fields constructed from tandem satellite altimeter datasets. J. Atmos. Oceanic Technol., 20, 1276-1302, https://doi.org/10.1175/1520-0426(2003)020<1276:TAOSSS> 2.0.CO;2.

Cheng, Y., and O. B. Andersen, 2011: Multimission empirical ocean tide modeling for shallow waters and polar seas. J. Geophys. Res., 116, C11001, https://doi.org/10.1029/ 2011JC007172.

Cummins, P. F., J. Y. Cherniawsky, and M. G. G. Foreman, 2001: North Pacific internal tides from the Aleutian Ridge: Altimeter observations and modeling. J. Mar. Res., 59, 167-191, https://doi.org/10.1357/002224001762882628.

Derber, J., and A. Rosati, 1989: A global oceanic data assimilation system. J. Phys. Oceanogr., 19, 1333-1347, https://doi.org/ 10.1175/1520-0485(1989)019<1333:AGODAS > 2.0.CO;2.

Dibarboure, G., C. M. Pujol, F. Briol, P.-Y. LeTraon, G. Larnicol, N. Picot, F. Mertz, and M. Ablain, 2011: Jason-2 in DUACS: First tandem results and impact on processing and products. Mar. Geod., 34, 214-241, https://doi.org/10.1080/ 01490419.2011.584826.

Foreman, M. G. G., P. F. Cummins, J. Y. Cherniawsky, and P. Stabeno, 2006: Tidal energy in the Bering Sea. J. Mar. Res., 64, 797-818, https://doi.org/10.1357/002224006779698341.

Fu, L., D. Chelton, P.-Y. LeTraon, and R. Morrow, 2010: Eddy dynamics from satellite altimetry. Oceanography, 23 (4), 1425, https://doi.org/10.5670/oceanog.2010.02.

Holgate, S. J., and Coauthors, 2013: New data systems and products at the Permanent Service for Mean Sea Level. J. Coastal Res., 29, 493-504, https://doi.org/10.2112/JCOASTRES-D-12-00175.1.

Kang, S. K., J. Chung, S. Lee, and K. Yum, 1995: Seasonal variability of the $M_{2}$ tide in the seas adjacent to Korea. Cont. Shelf Res., 15, 1087-1113, https://doi.org/10.1016/0278-4343(94)00066-V.

Lefevre, F., C. LeProvost, and F. H. Lyard, 2000: How can we improve a global ocean tide model at a regional scale? A test on the Yellow Sea and the East China Sea. J. Geophys. Res., 105, 8707-8725, https://doi.org/10.1029/1999JC900281.

LeTraon, P., F. Nadal, and N. Ducet, 1998: An improved mapping method of multisatellite altimeter data. J. Atmos. Oceanic Technol., 15, 522-534, https://doi.org/10.1175/1520-0426(1998) $015<0522$ :AIMMOM $>2.0 . \mathrm{CO} ; 2$.

Merrifield, M. A., 2011: A shift in western tropical Pacific sea level trends during the 1990s. J. Climate, 24, 4126-4138, https://doi.org/ 10.1175/2011JCLI3932.1.

Mertz, F., V. Rosmorduc, C. Maheu, and Y. Faugère, 2016: Product user manual for sea level SLA products. CMEMS version scope 2.0, Issue 2.4, Copernicus Marine Environmental Monitoring Service Tech. Rep. CMEMS-SL-PUM-008-017033, $73 \mathrm{pp}$. 
Mirouze, I., and A. Weaver, 2010: Representation of the correlation functions in variational data assimilation using an implicit diffusion operator. Quart. J. Roy. Meteor. Soc., 136, 1421, https://doi.org/10.1002/qj.643.

Morrow, R., and P.-Y. LeTraon, 2012: Recent advances in observing mesoscale ocean dynamics with satellite altimetry. Adv. Space Res., 50, 1062-1076, https://doi.org/10.1016/ j.asr.2011.09.033.

Parke, M. E., R. H. Stewart, D. L. Farless, and D. E. Cartwright, 1987: On the choice of orbits for an altimetric satellite to study ocean circulation and tides. J. Geophys. Res., 92, 11 693-11 707, https://doi.org/10.1029/JC092iC11p11693.

Pujol, M.-I., Y. Faugère, G. Taburet, S. Dupuy, C. Pelloquin, M. Ablain, and N. Picot, 2016: DUACS DT2014: The new multi-mission altimeter data reprocessed over 20 years. Ocean Sci., 12, 1067-1090, https://doi.org/10.5194/os-12-1067-2016.

Ray, R. D., and D. A. Byrne, 2010: Bottom pressure tides along a line in the southeast Atlantic Ocean and comparisons with satellite altimetry. Ocean Dyn., 60, 1167-1176, https://doi.org/ 10.1007/s10236-010-0316-0.

- and E. D. Zaron, 2016: Internal tides and their observed wavenumber spectra from satellite altimetry. J. Phys. Oceanogr., 46, 3-22., https://doi.org/10.1175/JPO-D-15-0065.1.

, G. D. Egbert, and S. Y. Erofeeva, 2011: Tide predictions in shelf and coastal waters: Status and prospects. Coastal Altimetry, S. Vignudelli et al., Eds., Springer, 191-216, https:// doi.org/10.1007/978-3-642-12796-0_8.
Ruiz Etcheverry, L. A., M. Saraceno, A. R. Piola, G. Valladeau, and O. O. Möller, 2015: A comparison of the annual cycle of sea level in coastal areas from gridded satellite altimetry and tide gauges. Cont. Shelf Res., 92, 87-97, https://doi.org/10.1016/ j.csr.2014.10.006.

Song, D., X. H. Wang, X. Zhu, and X. Bao, 2013: Modeling studies of the far-field effects of tidal flat reclamation on tidal dynamics in the East China Seas. Estuarine Coastal Shelf Sci., 133, 147-160, https://doi.org/10.1016/j.ecss.2013.08.023.

Stammer, D., and Coauthors, 2014: Accuracy assessment of global barotropic ocean tide models. Rev. Geophys., 52, 243-282, https://doi.org/10.1002/2014RG000450.

Vignudelli, S., A. G. Kostianoy, P. Cipollini, and J. Benveniste, Eds., 2011: Coastal Altimetry. Springer, 566 pp., https://doi. org/10.1007/978-3-642-12796-0.

Xie, D., S. Gao, Z. Wang, and C. Pan, 2013: Numerical modeling of tidal currents, sediment transport and morphological evolution in Hangzhou Bay, China. Int. J. Sediment Res., 28, 316-328, https://doi.org/10.1016/S1001-6279(13) 60042-6.

Zaron, E. D., 2015: Nonstationary internal tides inferred from dual-satellite altimetry. J. Phys. Oceanogr., 45, 2239-2246, https://doi.org/10.1175/JPO-D-15-0020.1.

Zhao, Z., M. H. Alford, J. Girton, T. M. Johnston, and G. Carter, 2011: Internal tides around the Hawaiian Ridge estimated from multisatellite altimetry. J. Geophys. Res., 116, C12039, https://doi.org/10.1029/2011JC007045. 